\title{
Implementasi Router Mikrotik dan Modem Mifi Smartfren sebagai Backup Akses Data dengan Menggunakan Sistem Failover
}

\author{
Muh. Asdar Arfan*1, Zahir Zainuddin ${ }^{2}$, Rahmania ${ }^{3}$ \\ ${ }^{1,3}$ Program Studi Teknik Elektro Universitas Muhammadiyah Makassar \\ ${ }^{2}$ Program Studi Teknik Elektro Universitas Hasanuddin Makassar \\ e-mail: muh.asdararfan96@gmail.com
}

\begin{abstract}
Along with the advancement of technology in the telecommunications sector, every government or private agency or office already has internet access. However, there are still a few offices that use this failover system that can support community services as is the case at the Makassar Ministry of Religion. This study aims to determine the configuration, performance and efficiency of the failover system. The method used to test the proxy tool and failover system to all users or clients contained in the office of the Ministry of Religion of Makassar, then carried out a trial of the system and then do a comparison of the number of users or clients contained in ISP 1 whether ISP 2 can backup all user or client contained in ISP 1, the results of the comparison failover system runs as expected and all users or clients contained in ISP 1 can be backed up properly by ISP 2 and it can be concluded that performance and efficiency in failover system usage and Smartfren as an ISP 2 is very helpful to maximize service to the community.
\end{abstract}

Kata kunci: mikrotik; failover system; smartfren mifi; offline; client

\begin{abstract}
Abstrak
Seiring dengan semakin majunya teknologi dibidang telekomunikasi maka setiap instansi atau kantor milik pemerintah atau swasta sudah memiliki akses internet. Namun, masih sedikit kantor yang menggunakan sistem failover ini yang dapat menunjang pelayanan masyarakat seperti halnya yang terjadi di kantor kementerian agama kota Makassar. Pada penelitian ini bertujuan untuk mengetahui konfigurasi, kinerja dan efesiensi dari sistem failover tersebut. Metode yang digunakan melakukan pengujian alat mikrotik dan sistem failover tersebut kepada seluruh user atau client yang terdapat pada kantor kementerian agama kota Makassar, kemudian dilakukan uji coba terhadap sistem tersebut lalu melakukan perbandingan jumlah user atau client yang terdapat di ISP 1 apakah ISP 2 dapat membackup seluruh user atau client yang terdapat pada ISP 1, hasil dari perbandingan tersebut sistem failover tersebut berjalan sebagai mana yang di harapkan dan seluruh user atau client yang terdapat pada ISP 1 dapat terbackup dengan baik oleh ISP 2 dan dapat disimpulkan bahwa kinerja dan efesiensi dalam penggunaan sistem failover dan mifi smartfren sebagai ISP 2 ini sangat membantu untuk memaksimalkan pelayanan kepada masyarakat.
\end{abstract}

Kata kunci: mikrotik; sistem failover; mifi Smartfren; offline; client

\section{Pendahuluan}

Perkembangan dunia telekomunikasi semakin hari semakin maju tidak bisa dipungkiri lagi bahwa setiap orang harus terhubung dengan internet baik itu secara perorangan maupun perkelompok. Di era saat ini pertukaran file sudah dapat dilakukan dengan cepat bahkan jarak sudah bukan lagi halangan. Oleh sebab itu setiap instansi atau kantor milik pemerintah maupun swasta harus memeliki akses internet yang dimana dapat menunjang kinerja setiap pegawainya dalam hal mengiriman data atau pun sebaliknya.

Namun dalam menyediakan akses internet di beberapa instansi atau kantor milik pemerintah contohnya seperti kantor kementerian agama kota Makassar ditemukan hal yang tidak wajar yaitu seringnya terjadi gangguan koneksi internet yang dimana dapat mengganggu kinerja pegawai dalam mengerjakan laporan dan melakukan pelayanan terhadap masyarakat yang ingin melaksanakan umrah dan haji. 
Sehingga dengan diimplementasikannya system failover ini maka kantor kementerian agama dikota Makassar akan memiliki 2 jaringan ISP (Internet service provider). Sistem failover ini dapat melakukan perpindahan jaringan internet secara otomatis ke link backup apabila link utama tiba-tiba mati atau offline.

\section{Metode Penelitian}

Metode penelitian terbagi ke dalam beberapa tahap di mulai dari lokasi penelitian, pengumpulan data, dan langkah-langkah penelitian.

\subsection{Lokasi dan Waktu Penelitian}

Lokasi pengambilan data pada penelitian ini dilakukan di Kantor Kementerian Agama Kota Makassar dan Waktu pelaksanaan penelitian mulai di bulan maret 2018.

\subsection{Pengumpulan Data}

Pengumpulan data pada penelitian ini adalah sebagai berikut:

- Metode kepustakaan yaitu mencari literature yang berhubungan dengan penelitian ini yang digunakan untuk menambah teori-teori dasar dan sebagai sarana pendukung dalam menganalisa masalah yang terjadi.

- Metode Observasi yaitu pengambilan data pada Kementerian Agama Kota Makassar, serta melakukan analisis terhadap data yang diperoleh.

- Metode Tanya Jawab yaitu Tanya jawab secara langsung dengan pembimbing di Kementerian Agama Kota Makassar yang digunakan untuk mendukung teori dari data yang telah diperoleh.

\subsection{Langkah-Langkah Penelitian}

Penelitian yang dilakukan memiliki beberapa tahapan sebagai berikut :

- Pengambilan data dilakukan di Kantor Kementerian Agama Kota Makassar.

- Adapun teknik data yang dipergunakan dalam penelitian ini, yaitu : Data diperoleh dari hasil penelitian di kementerian agama kota Makassar dengan menghitung jumlah client yang terbackup oleh ISP 2 setelah jaringan ISP 1 di nonaktifkan sementara waktu.

- Pada pengambilan data penulis mencatat jumlah client yang aktif pada saat jaringan ISP 1 yang aktif.



Gambar 1. Pengolahan Data ISP 1

Keterangan :

ISP 1 adalah link utama

ISP 2 adalah link backup atau cadangan

Mikrotik adalah perangkat keras

Client adalah pengguna

Jalur internet aktif

_ Jalur internet tidak aktif 
- Sebelum pengambilan data client untuk ISP 2, router mikrotik dikonfigurasi menggunakan aplikasi winbox untuk menjalankan sistem failover. Kemudian untuk pengambilan data, penulis mencatat jumlah client yang bisa terbackup oleh ISP 2 setelah ISP 1 tidak aktif.

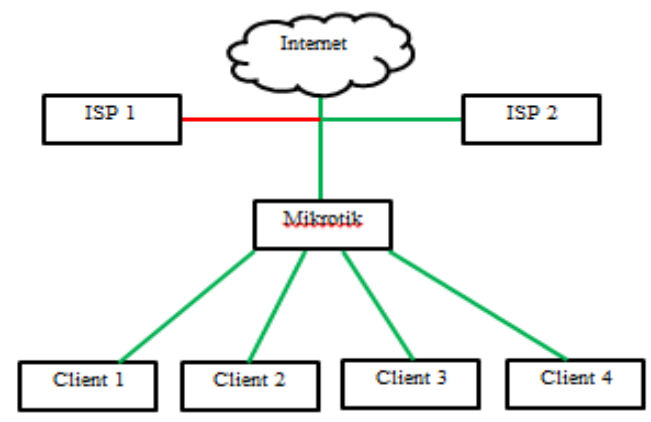

Gambar 2. Pengolahan Data ISP 2

\section{Hasil dan diskusi}

Hasil penelitian mengenai konfigurasi Modem Mifi Smartfren, konfigurasi koneksi internet Mifi dan Telkom dan konfigurasi lainnya akan disajikan berikut ini.

\subsection{Konfigurasi Modem Mifi Smartfren}

- Sambung modem mifi smartfren ke laptop menggunakan kabel data.

- Secara otomatis modem akan membuka browser dan akan mengantarkan ke halaman login dari modem mifi, lalu mengisi kolom nama pengguna dengan admin dan kolom kata sandi dengan admin, selanjutnya mengklik masuk.

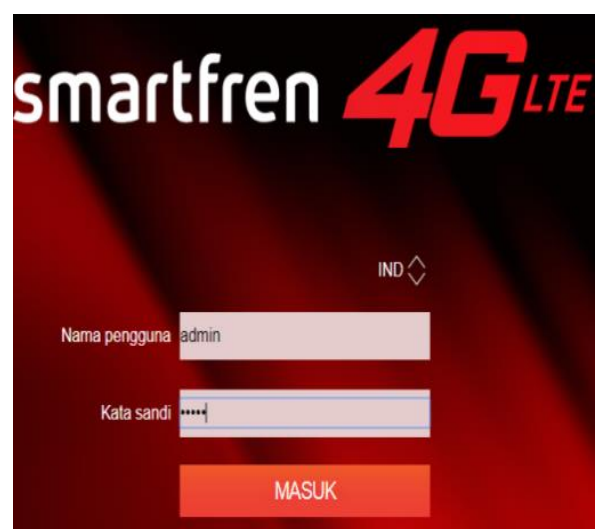

Gambar 3. Halaman login modem Mifi Smartfren

- Kemudian pada menu pengaturan dengan memilih menu tab WLAN. Lalu memilih pengaturan dasar WLAN, nonaktifkan SSID kemudian terapkan. 


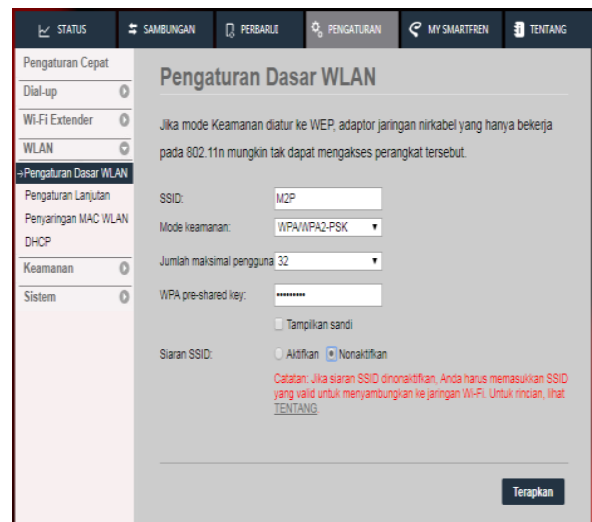

Gambar 4. Pengaturan dasar WLAN modem Mifi Smartfren

- Kemudian memilih menu tab Dial-up lalu pilih sambungan seluler, ganti mode sambungan menjadi otomatis lalu mengklik terapkan. Selanjutnya melepas kabel data dari laptop kemudian memasang modem ke router mikrotik dibagian konektor USB.

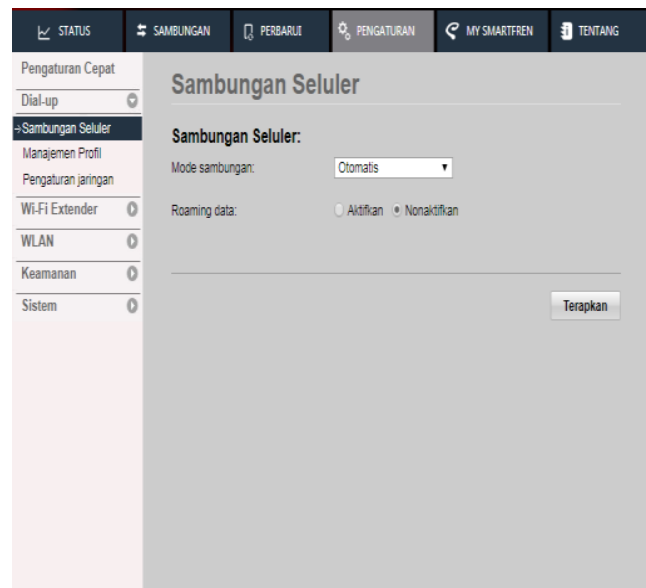

Gambar 5. Pengaturan sambungan selular modem mifi smartfren.

\subsection{Konfigurasi koneksi internet Mifi dan Telkom}

- Konfigurasi LTE di mikrotik menggunakan aplikasi winbox, dengan menyambungkan laptop dan router mikrotik dengan menggunakan kabel lan.

- Kemudian menjalankan aplikasi winbox, kemudian mengklik neighbors, kemudian memilih mac address atau ip address pada router mikrotik, lalu mengklik connect.

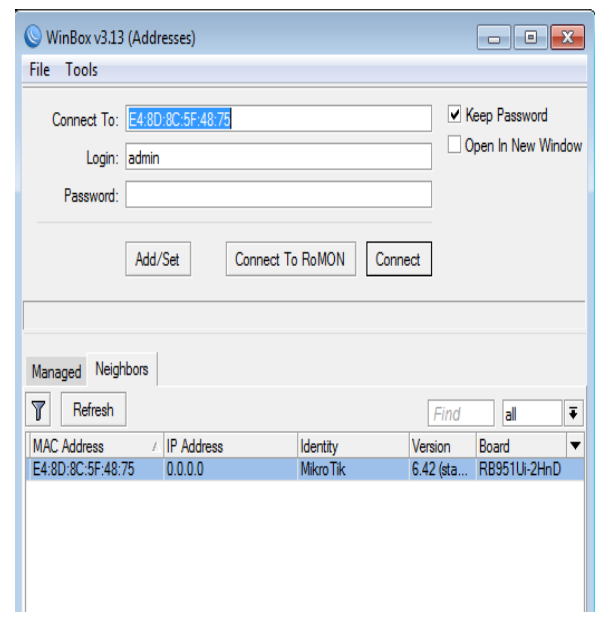

Gambar 6. Aplikasi winbox 
- Lalu mengklik menu interface kemudian memilih Ite, kemudian mengganti namanya menjadi ANDROMAX.

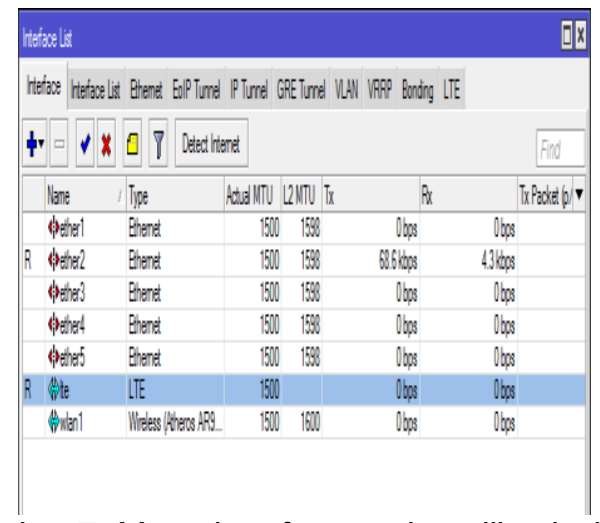

Gambar 7. Menu interface pada aplikasi winbox

Pengaturan NAT pada interface LTE. Memilih menu terminal lalu memasukkan coding /ip firewall nat add chain=srcnat out-interface=ANDROMAX action=masquerade

- Memasang kabel utp pada port 1 di modem Telkom dan pada ether 1 di router mikrotik untuk koneksi internet ISP 1 . Pengaturan NAT pada interface ether 1 yaitu memilih menu terminal lalu memasukkan coding /ip firewall nat add chain=srcnat out-interface=ether1 action=masquerade.

\subsection{Pengaturan WLAN}

- Kemudian memilih menu wireless kemudian masuk ke tab menu security profiles lalu memilih tanda tambah untuk membuat password yang nanti digunakan untuk mengakses wifi dari mikrotik.

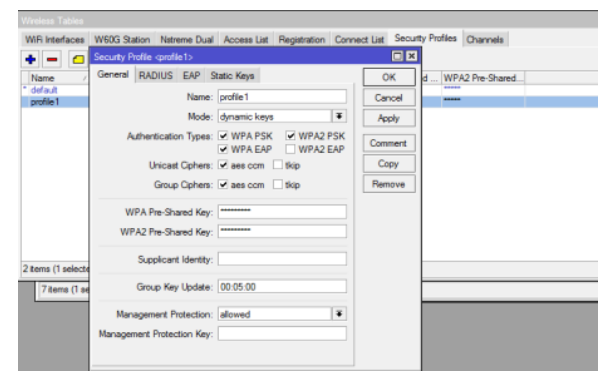

Gambar 8. Konfigurasi securtiy profile pada interface wlan

Kemdian mengcentang pengaturan WPA PSK, WPA EAP, aes com pada unicast ciphers dan group ciphers. Lalu mengisi kolom WPA Pre-Shared key dan WPA2 Pre-Shared key sebagai password wifi dari router mikrotik.

- Lalu masuk ke menu wifi interface, memilih wlan1 kemdian tab menu wireless. Ubah mode menjadi ap bridge, ubah SSID menjadi KEUANGAN, lalu pada security profile ubah menjadi profilel. Kemudian apply, untuk mengaktifkannya dengan memilih tanda centang pada bagian atas. 


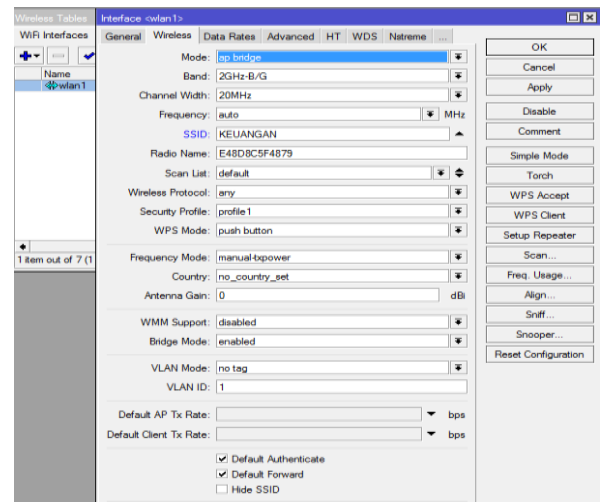

Gambar 9. Konfigurasi wireless pada interface WLAN

- Untuk membuat ip address untuk wifi, memilih menu ip kemudian memilih addresses. Isi kolom address dan network dengan ip address, lalu ganti interface menjadi wlan 1 kemudian mengklik ok.



Gambar 10. Konfgurasi ip address wlan

- Masuk ke menu ip lalu pilih DHCP Server, pada menu DHCP memlih tab menu DHCP Setup. Kemudian akan muncul window pilih interface wlan1 lalu mengklik next sampai akhirnya muncul pesan bahwa DHCP Server telah selesai.

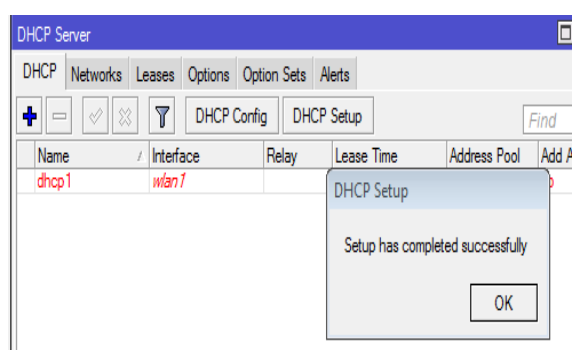

Gambar 11. Konfigurasi DHCP server yang selesai

\subsection{Konfigurasi Failover}

- Memilih menu IP kemudian masuk ke menu Routes, buat new route. Mengisi pada kolom gateway dengan memasukkan ip address dari ether1 kemudian ubah distance menjadi 1 lalu ok. 




- Memilih menu interface lalu tab menu LTE masuk ke menu LTE APNs kemudian akan muncul window baru memilihs item default kemudian mucul window LTE APN ubah menjadi 2 pada kolom Default Route Distance lalu ok.

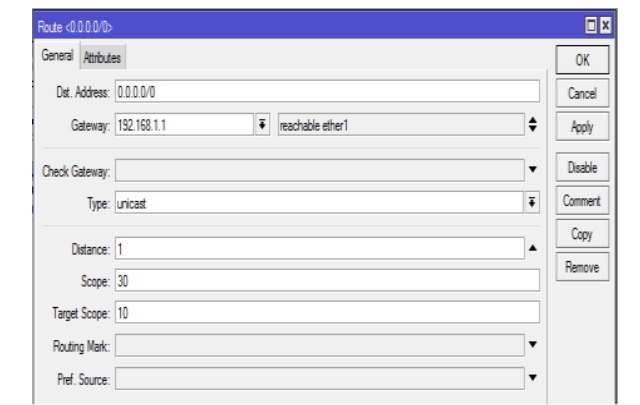

Gambar 13. Konfigurasi route pada ISP 2

\subsection{Pengambilan Data Jumlah User Yang Terbackup}

Seluruh user diarahkan menggunakan wifi yang terdapat pada mikrotik yang sudah dikonfigurasi bahwa ISP 1 adalah Telkom dan ISP 2 adalah Mifi Smartfren. Setelah itu ditampilankan seluruh user atau client yang sudah terkoneksi dengan mikrotik.Koneksi internet akan diarahkan ke ISP 1 oleh router mikrotik, kemudian dilakukan pengujian pada salah satu client atau user dengan cara tracert ke website sulsel.kemenag.go.id dan youtube.com. Kemudian akses data koneksi internet pada ISP 1 akan di offlinekan sementara waktu, maka secara otomatis router mikrotik akan mengalihkan akses data koneksi internet ke ISP 2 disebabkan koneksi internet pada ISP 1 mengalami offline.

Pada saat pengalihan akses data koneksi internet dari ISP 1 ke ISP 2 beberapa user atau clien harus mengalami buffering beberapa detik, sebab router mikrotik sedang memindahkan akses data koneksi internet ke ISP 2. Setelah perpindahan tersebut, hasilnya seluruh user atau client dapat dibackup oleh ISP 2. Kemudian dilakukan kemudian dilakukan pengujian pada salah satu client atau user dengan cara tracert ke website sulsel.kemenag.go.id dan youtube.com. Selanjutnya melakukan pengetesan kecepatan internet pada ISP 2 menggunakan website www.speedtest.net dan hasilnya kecepatan ping mencapai $86 \mathrm{~ms}$, kecepatan download 5,48 mbps, dan kecepatan upload 2,06 mbps. Dari hasil pengetesan kecepatan internet pada modem Mifi Smartfren tersebut dapat dinyatakan bias menggantikan peran ISP 1 dalam menyediakan koneksi internet ke semua client atau user yang terdapat pada ISP 1.

Apabila akses data koneksi internet dari ISP 1 sudah kembali online maka router mikrotik akan memindahkan secara otomatis koneksi internet dari ISP 2 ke ISP 1. Kemudian user atau client akan kembali mengalami buffering beberapa detik akibat dari perpindahan otomatis koneksi internet yang dilakukan router mikrotik tersebut

\section{Kesimpulan}

Konfigurasi sistem failover yang diterapkan pada router mikrotik dapat bekerja dengan baik yaitu pada saat akses data koneksi internet pada ISP 1 (Telkom) mengalami offline maka secara otomatis ISP 2 (Mifi smartfren) akan bertindak sebagai pembackup akses data koneksi 
internet. Pada saat ISP 1 mengalami offline, maka koneksi internet pada seluruh user atau client akan dibackup oleh ISP 2 sebab kinerja dan efesiennya dalam membackup akses data sudah menggunakan jaringan LTE.

\section{Referensi}

[1] I. Riadi, "Optimalisasi Keamanan Jaringan Menggunakan Pemfilteran Aplikasi Berbasis Mikrotik," J. JUSI, vol. 1, no. 1, 2011.

[2] N. F. Zamzami and P. Telkom, "Implementasi load balancing dan failover menggunakan mikrotik router os berdasarkan multihomed gateway pada warung internet" diga"," DIGA'”,', Skripsi. UDINUS Indones., 2013.

[3] N. F. Puspitasari, "Implementasi Mikrotik sebagai solusi router murah dan mudah," in Yogyakarta: Seminar Nasional Teknologi, 2007.

[4] F. Fitriastuti and D. P. Utomo, "IMPLEMENTASI BANDWDITH MANAGEMENT DAN FIREWALL SYSTEM MENGGUNAKAN MIKROTIK OS 2. 9. 27," J. Tek., vol. 4, 2014.

[5] R. Pambudi and M. A. Muslim, "Implementasi Policy Base Routing dan Failover Menggunakan Router Mikrotik untuk Membagi Jalur Akses Internet di FMIPA Unnes," J. Teknol. dan Sist. Komput., vol. 5, no. 2, pp. 57-61, 2017. 